\title{
A Method to Assess Localized Impact of Better Floodplain Topography on Flood Risk Prediction
}

\author{
Guy J.-P. Schumann ${ }^{1,2}$ and Konstantinos M. Andreadis ${ }^{3}$ \\ ${ }^{1}$ Remote Sensing Solutions, Inc., Monrovia, CA 91016, USA \\ ${ }^{2}$ School of Geographical Sciences, University of Bristol, Bristol BS8 1SS, UK \\ ${ }^{3}$ NASA Jet Propulsion Laboratory, California Institute of Technology, Pasadena, CA 91109, USA
}

Correspondence should be addressed to Guy J.-P. Schumann; gjpschumann@gmail.com

Received 23 January 2016; Revised 3 May 2016; Accepted 17 May 2016

Academic Editor: Maoyi Huang

Copyright (C) 2016 G. J.-P. Schumann and K. M. Andreadis. This is an open access article distributed under the Creative Commons Attribution License, which permits unrestricted use, distribution, and reproduction in any medium, provided the original work is properly cited.

\begin{abstract}
Many studies have highlighted the need for a higher accuracy global digital elevation model (DEM), mainly in river floodplains and deltas and along coastlines. In this paper, we present a method to infer the impact of a better DEM on applications and science using the Lower Zambezi basin as a use case. We propose an analysis based on a targeted observation algorithm to evaluate potential data acquisition subregions in terms of their impact on the prediction of flood risk over the entire study area. Consequently, it becomes trivial to rank these subregions in terms of their contribution to the overall accuracy of flood prediction. The improvement from better topography data may be expressed in terms of economic output and population affected, providing a multifaceted assessment of the value of acquiring better elevation data. Our results highlight the notion that having higher resolution measurements would improve our current large-scale flood inundation prediction capabilities in the Lower Zambezi by at least $30 \%$ and significantly reduce the number of people affected as well as the economic loss associated with high magnitude flooding. We believe this procedure to be simple enough to be applied to other regions where high quality topographic and hydrodynamic data are currently unavailable.
\end{abstract}

\section{Introduction}

Topographic information in the form of a digital elevation model (DEM) is required for many environmental process models and applications. In many cases, the accuracy of a DEM is determining the performance of the model applied and the success of the application. Different technologies exist to acquire land elevation, often with varying degrees of accuracy and precision depending on the technology and resolution used. Remote sensing is commonly used to measure topography and instruments typically include altimeters (radar or LiDAR), synthetic aperture radar (SAR) interferometry, and photogrammetry from optical imagery; even unmanned aerial vehicles (UAV) are being used more recently to acquire DEMs. Vertical errors can range from several meters, typical for satellite DEM technology, for example, from the Shuttle Radar Topography Mission (SRTM, http://www2.jpl.nasa.gov/srtm/) or ASTER, down to the decimeter in the case of airborne LiDAR, airborne photogrammetry, and also novel airborne single-pass SAR interferometry as recently demonstrated by Schumann et al. [1].

Although accurate topography is desirable and in many cases a prerequisite for successful modeling, it is often not available at the required accuracy level and resolution for many areas around the world. As argued by Schumann et al. [2], there is a need for a higher accuracy (LiDAR-type) global DEM than currently available, particularly for mapping and predicting natural hazards such as flooding in developing countries that are often deprived but in need of a high quality DEM.

For instance, Mozambique (SE Africa) comprises a large flood-prone region in the downstream part of the Zambezi River Basin (ZRB), including a vast delta ecosystem and a number of important wetlands. Human activities, mostly related to hydroelectric power generation and agriculture, 
have led to considerable alteration of the basin's hydrology and (natural) flooding pattern [3]. High magnitude flooding in the region happens regularly in the monsoon season but in some cases the impact is exacerbated through dam release operations such as, for instance, during the devastating floods of 2000. According to EM-DAT (http://www.emdat.be/, the Centre for Research on the Epidemiology of Disasters' Emergency Events Database), over the last 20 years (1995-2015), there have been more than 150 flood occurrences within the $\mathrm{ZRB}$, affecting over 17 million people in total and causing total damage of over $\$ 1$ billion US dollars, with single events being able to affect more than a million people at a time and many millions of US dollars in damage. These figures are alarming, even more so since many ZRB countries do not have any effective flood risk management plan in place and do only have very limited flood forecasting capabilities [4], and hence setting up some capabilities to improve current flood risk management in the ZRB countries, albeit with limited means and considerable efforts, is desperately needed.

In this context, Schumann et al. [5] demonstrated the value of remotely sensed data to build, calibrate, and validate a large-scale 2D hydrodynamic LISFLOOD-FP model (operating on a regular grid where water flow is simulated by solving the inertial momentum equation through a single explicit finite difference scheme; see [6]) forced with forecast flood flows to predict floodplain inundation depth and extent in the Lower Zambezi. In conclusion, they noted that although first efforts are encouraging, considerable improvements in the modeling, forcing data, and boundary conditions are needed to achieve greater forecasting capabilities, among which collecting finer resolution and better accuracy floodplain topography was considered particularly important. About $1000 \mathrm{~km}$ of river flow length and a floodplain area of around $40,000 \mathrm{~km}^{2}$ were considered in this study (Figure 1). According to a simulation with the LISFLOOD-FP model of Schumann et al. [5], a 1:10,000 return period flow event estimated at $\sim 30,000 \mathrm{~m}^{3} \mathrm{~s}^{-1}$ [7] would inundate approximately $8,000 \mathrm{~km}^{2}$ of floodplain. These are large areas to cover with any airborne platform for high resolution topographic mapping which may render the cost of aircraft operation and data acquisition and processing prohibitive. However, the acquisition of better floodplain topography in the lower portion of the ZRB has the potential to significantly improve prediction and management of flood hazard and risk in the region, particularly Mozambique. Consequently, prioritization of the areas of data acquisition would help optimize operations such as flight lines and management of resources.

In this paper, we present a method to objectively identify areas for DEM acquisition based on floodplain hydrodynamics. We demonstrate that the method intrinsically pinpoints locations where a (flood forecasting) model would benefit most from better boundary condition data, in this case higher resolution floodplain topography. We further illustrate that, by including auxiliary datasets such as economic and population data, one can improve not only the selection of areas but potentially also flood risk management for those locations.

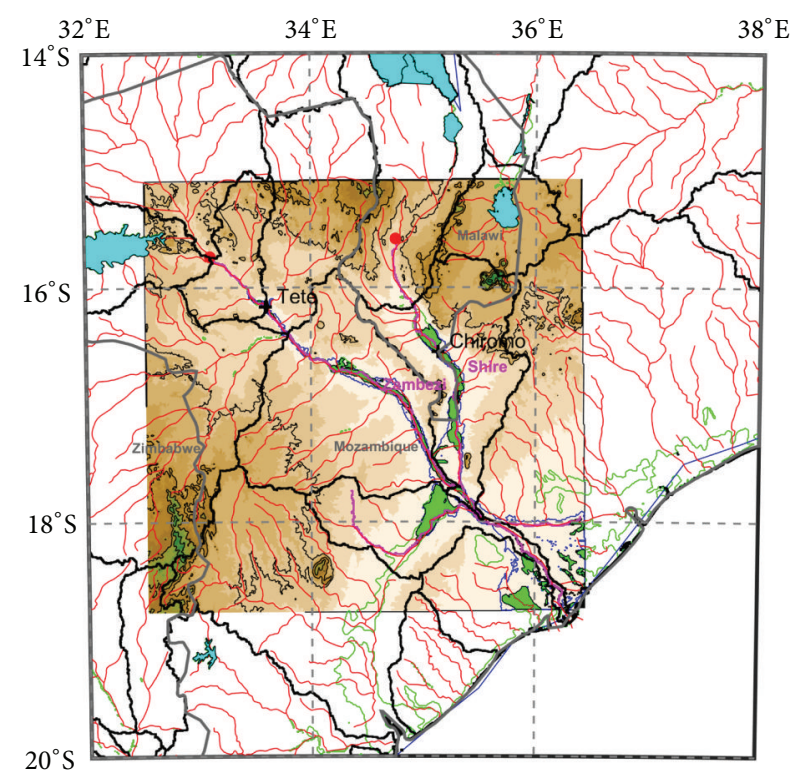

FIGURE 1: Map of modeling domain. Land elevations from SRTM are shown in shades of brown, the two main rivers (Zambezi and Shire) are shown in pink, and the inflow locations are depicted by red dots. The flooded area outline of the 1:10,000 year event is shown in blue. Large reservoirs are colored with cyan, wetlands are in green, and other rivers in the region are in red.

In the next section, we describe the method, followed by a brief section of results and discussion and finally a conclusion section.

\section{Methods}

2.1. Estimating the Impact of Better Topography on Flood Hazard Prediction. The impact of better floodplain topography, for example, acquired, for instance, by airborne LiDAR or InSAR as opposed to SRTM, on the estimation of flood hazard variables (e.g., flooded area) can be assessed using the targeted observation method proposed by Andreadis and Schumann [8]. This involves the ingestion of measurements or observations over a "targeted area" into a hydrodynamic model and the estimation of flooded area (in our case) without rerunning the model. An optimal estimation algorithm (1) exploits the statistical relationships between variables to make a prediction. The cost function that measures the reduction in the prediction error due to the assimilation of new measurements, that is, the measurement impact, is defined as

$$
\begin{aligned}
& J=\frac{1}{2}\left(e_{t \mid 0}^{T} e_{t \mid 0}-e_{t \mid-1}^{T} e_{t \mid-1}\right), \\
& \text { where } e_{t \mid 0}=\bar{x}_{t \mid 0}^{f}-\bar{x}_{t}^{a}, e_{t \mid-1}=\bar{x}_{t \mid-1}^{f}-\bar{x}_{t}^{a} .
\end{aligned}
$$

The cost functional $J$ is the difference of the squared errors between the model run that benefits from the new measurements and the model that does not benefit from any new measurements being assimilated. Variable $\bar{x}_{t \mid-1}^{f}$ is the model prediction without any assimilation and $\bar{x}_{t \mid 0}^{f}$ is the prediction 
with the new measurement assimilated. The verification $\bar{x}_{t}^{a}$ at time $t$ can be either an actual measurement or the analysis at time $t$, implicitly assumed to be more accurate than both model runs. Applying the Local Ensemble Transform Kalman Filter (LETKF) analysis formulation after Hunt et al. [9], the cost functional $J$ can be computed to represent the sensitivity of a prediction skill to the measurements being assimilated. For more details on the derivation of $J$ in a LETKF sensitivity experiment, the reader is referred to Andreadis and Schumann [8] as well as Liu and Kalnay [10].

In our case, applying this method means that the impact (expressed by $J$ ) of higher resolution topography on the simulated flooded area can be estimated. Since better topography measurements have not actually been acquired (yet) over the Lower Zambezi, the impact assessment is simulated. Assuming that the $1 \mathrm{~km}$ resolution inundation forecast model by Schumann et al. [5] represents current modeling capabilities at large scales (see also Sampson et al. [11] for a state-of-theart global simulation of inundation based on the same model type) and that existing elevation datasets over large scales can be obtained at a spatial resolution of $90 \mathrm{~m}$ or less, we ran a 2D LISFLOOD-FP simulation using the $90 \mathrm{~m}$ SRTM-DEM in order to emulate the minimum difference that a higher resolution floodplain topography would most likely achieve.

Since the amount and timing of floodplain inundation are largely determined by in-channel water level and floodplain topography controls floodplain flow and thus inundation extent, we sampled water levels from the $90 \mathrm{~m}$ model output (based on subreaches determined from a first-order hydraulic analysis; see Section 3 for more details) and assimilated those in the $1 \mathrm{~km}$ baseline model. Note that better topography would of course also improve the estimation of river bank heights which control the timing and location of flood waters overtopping, particularly in the $1 \mathrm{~km}$ model version since LISFLOOD-FP SGC inverts bank heights to estimate channel bathymetry using hydraulic geometry [12].

We then use the simulated flooded area from the $1 \mathrm{~km}$ model (before and after assimilation) and compare that to the inundated area of the $90 \mathrm{~m}$ model which represents the verification. In other words, for the experimental design, both model versions are based on the SRTM-DEM topography but at two different spatial resolutions: (i) the $1 \mathrm{~km}$ resolution model that represents the "open-loop" simulation as well as the resulting model after assimilation and (ii) the $90 \mathrm{~m}$ model resolution that serves as the "verification" model for the $1 \mathrm{~km}$ models. Following this setup, the proposed targeted observation algorithm allows estimating the flooded area over the entire model reach that would be produced by a model utilizing better topography over the particular subregion (i.e., location of assimilation) only, and $J$ is a direct measure of the improvement in prediction achieved.

\subsection{Estimating the Associated Socioeconomic Impact. Esti-} mating the actual costs related to flood risk, that is, flood economic impact combined with flood hazard, may prove difficult in regions that have only limited amounts of relevant local data available, such as stage-damage curves and information on residential and nonresidential building, agricultural and industrial activities, and transportation. The unavailability and/or the poor quality of such socioeconomic data, primarily in developing countries, is often hindering efforts to understand and link environmental disasters to actual impacts on economy and society. Nonetheless, a number of approaches have been proposed more recently that use other measurements as proxies for economic statistics. One promising approach uses satellite-based luminosity, which measures nighttime lights to statistically characterize population, poverty, and economic productivity (e.g., [1315]). Measurements of nighttime lights are acquired from satellite sensors at relatively high spatial resolutions $(1 \mathrm{~km})$ globally and have been successfully used in the aforementioned studies showing strong correlations with economic activity, measured by the Gross Domestic Product (GDP), for instance. Here, we used nighttime image data from the US Department of Defense satellites for 2012 (most recently available) that contain lights from cities, towns, and locations with permanent lighting.

GDP data over the Lower Zambezi region were obtained from the G-Econ project (http://gecon.yale.edu/), which provides global economic data at $\sim 100 \mathrm{~km}$ resolution. Although these data are valuable, their coarse resolution can make the economic analysis of flood impacts difficult. Therefore, the GDP data were downscaled using the much finer resolution luminosity data. The latter were first aggregated to a $100 \mathrm{~km}$ grid to match the resolution of the GDP data grid, and then a ratio of GDP to luminosity was calculated. This ratio was then downscaled to $1 \mathrm{~km}$ by using a nearest-neighbor interpolation, and finally a fine resolution GDP value was calculated by multiplying the downscaled ratio with the original $1 \mathrm{~km}$ luminosity data.

Additionally, data on population density for 2015 (at a $\sim 4 \mathrm{~km}$ resolution) were acquired from the NASA Socioeconomic Data and Applications Center (SEDAC, http://sedac .ciesin.columbia.edu/) and integrated with the overall analysis, which as a result now provides a multifaceted assessment (i.e., physical and socioeconomic) of the full value of acquiring better elevation data.

\section{Results and Discussion}

As described in Section 2, we simulated flood inundation in the Lower Zambezi with a $1 \mathrm{~km}$ resolution LISFLOODFP hydrodynamic model. This model is identical to that of Schumann et al. [5] and we assume for the purpose of this study that it represents current flood modeling capabilities at large scales. The model is LISFLOOD-FP [6] in subgrid channel (SGC) mode [12] forced with forecast flood flows for the Zambezi and Shire Rivers simulated by the Variable Infiltration Capacity (VIC) distributed hydrology model, which is conditioned on meteorological ensemble forecast (ENS) data from ECMWF. For the complete setup, modeling chain, and model calibration, the reader is referred to Schumann et al. [5]. As in their study, we simulated the 2007 flood event and validation with a Landsat image shows a flood edge agreement to within one model resolution (mean distance to observed flood edge: $\sim 1.5 \mathrm{~km}$ ).

As outlined in Section 2, we build a $90 \mathrm{~m}$ version of a LISFLOOD-FP model that served as verification of the 


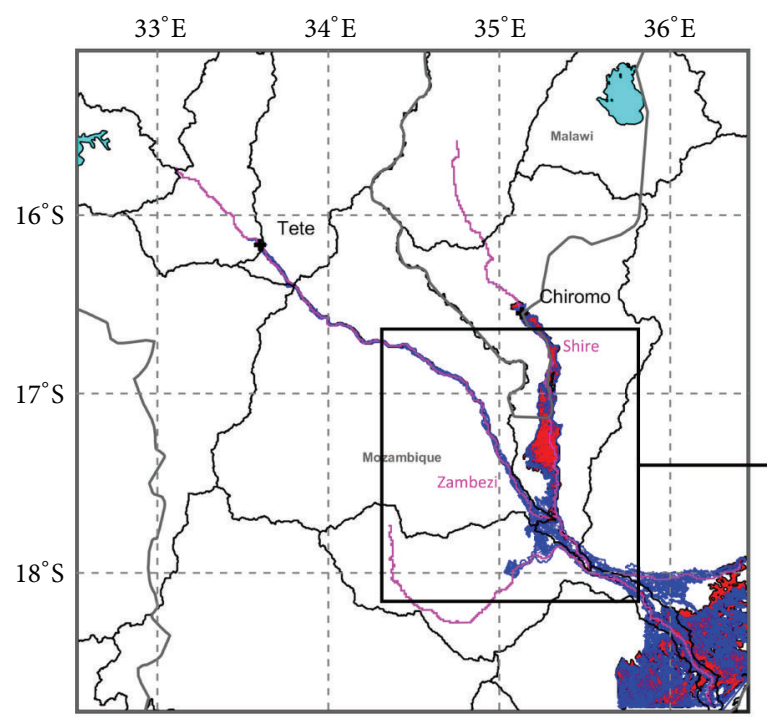

(a)

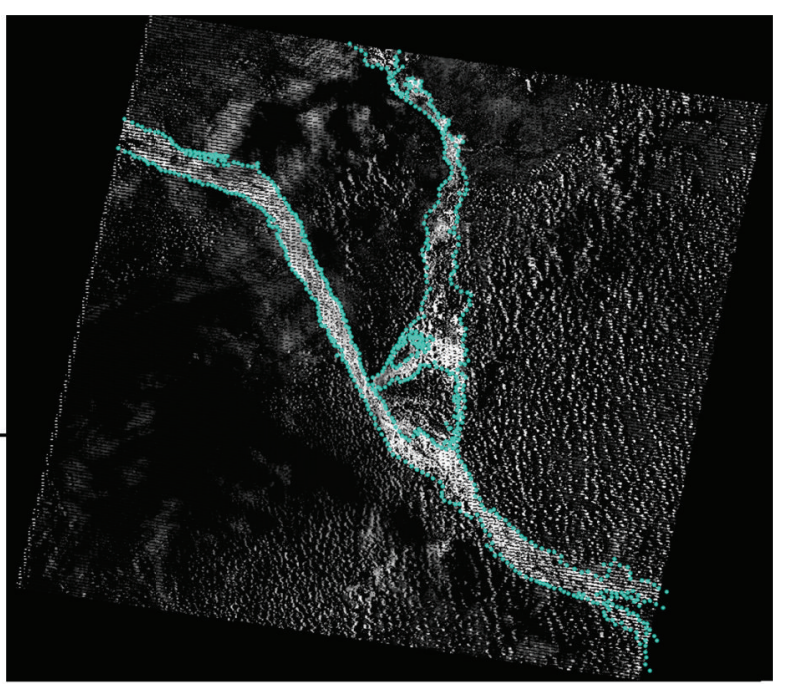

(b)

Figure 2: Map of the area (a) shows the flooded area simulated by the $1 \mathrm{~km}$ baseline model (red) and the $90 \mathrm{~m}$ verification model (blue). (b) depicts the corresponding Landsat image (of the 2007 flood event shown in white) and derived flood edge (depicted by blue dots).

targeted observation algorithm. For this model, we used the $90 \mathrm{~m}$ SRTM and deepened the channel area by interpolating the bathymetry simulated by the $1 \mathrm{~km}$ SGC model, allowing a full $2 \mathrm{D}$ inundation simulation at $90 \mathrm{~m}$ resolution. Figure 2 shows the flooded area from both models for the 2007 event as well as the Landsat image used for validation. Unsurprisingly, the extent of the $90 \mathrm{~m}$ model matches the Landsat flood edge more closely than that of the $1 \mathrm{~km}$ model with a mean distance to flood edge of $\sim 220 \mathrm{~m}$, at least four orders of magnitude better than the $1 \mathrm{~km}$ model.

For the targeted observation analysis, we simulated the 1:10,000 year event shown in Figure 1 to ensure we inundate most of the rivers' natural floodplains. Furthermore, since airborne data acquisition is likely to cover a spatial extent smaller than that of the entire floodplain area in the domain shown in blue in Figure 1, we defined a regional sampling strategy based on first-order in-channel hydraulics. We define a subreach based on bank height variations from the $90 \mathrm{~m}$ SRTM-DEM for a channel length (in flow distance) of constant river width taken from Andreadis et al. [16]. In addition, we computed the linear gradient of the SRTMderived thalweg (i.e., the kinematic wave form) and compared this to subreach characteristics (Figure 3), which constitutes a first step at understanding reach behavior and can help interpret the results of our targeted observation analysis.

Figure 3 shows the result of the first-order in-channel hydraulic analysis. Figure 3(a) shows the SRTM bank height variations along the river chainage and their deviation from a linear approximation of each subreach (red dashed lines). Also shown is a kinematic wave form along the entire main stem analyzed (blue line). Figure 3(b) shows for each subreach the deviation from this simple kinematic flow line. Interesting to note is that we can now observe those subreaches that exhibit a more diffusive channel flow behavior, that is, those that have a standard deviation from the kinematic wave approximation (along the entire river) greater than $2 \sigma$ (two standard deviations), for instance.

Of course, only subreaches with an associated inundation area (according to the $1: 10,000$ year event) are used (Figure 4) to set the sampling location of in-channel water levels from the $90 \mathrm{~m}$ model to be assimilated in the $1 \mathrm{~km}$ flood model.

Subsequently, we applied (1) to assess the impact better measurements of a river and floodplain subreach will have on the overall (global) reach being considered. Table 1 shows the results of the targeted observation analysis along with the associated economic costs of flood loss and monetary value gained from higher resolution (topography) measurements.

Each row in Table 1 corresponds to an individual region being the only one measured. The global improvement in flooded area is the improvement in prediction of flooded area for the entire model domain, while the regional improvement is the flooded area estimation improvement achieved localized for that region. For example, if better topography measurements were only acquired over subregion 1 and less accurate topography (i.e., SRTM-DEM) was used for the rest of the basin, there would be a $24 \%$ improvement in flooded area prediction relative to only using SRTM data. Moreover, the improvement that would be achieved for subregion 1 is $77.8 \%$ in terms of flooded area. It can be deduced that the percentage of improvement essentially describes the extent to which more accurate flooded area prediction is governed by topography, with the remainder being attributed to other hydraulic controls such as boundary conditions, for example, inflows. If all the latter were known and accurate, the regional error in flooded area prediction can be expected to reduce significantly.

Our analysis shows that having better topography measurements even only for a limited number of regions would improve prediction of flood hazard along the entire Zambezi main stem considerably, albeit with some uncertainty. 


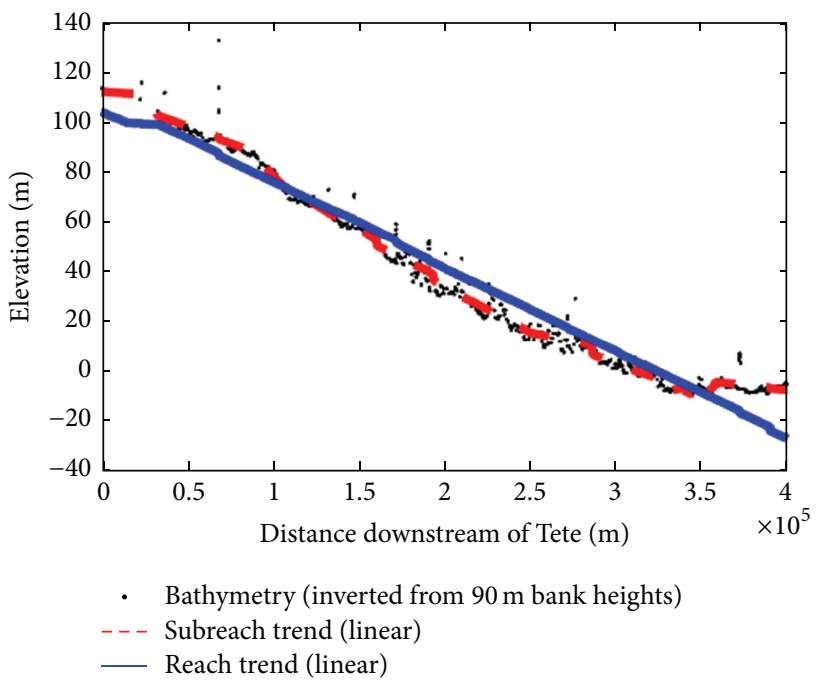

(a)

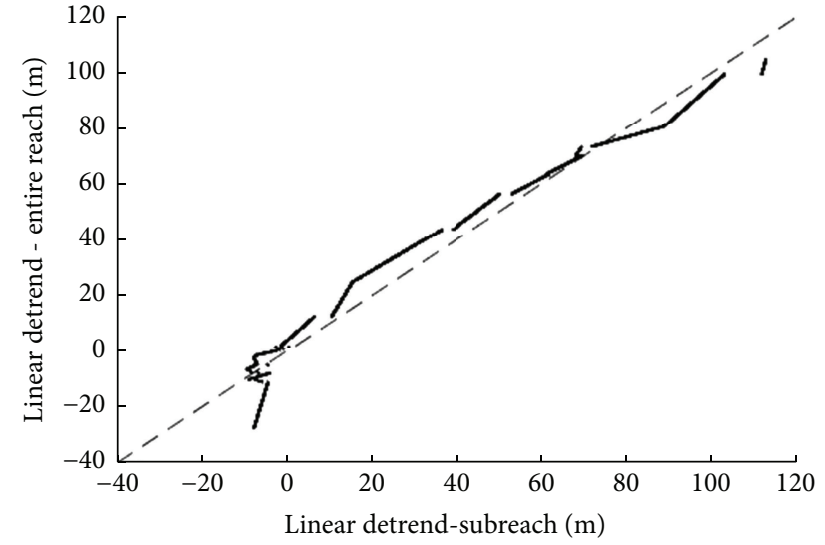

(b)

FIgURE 3: The graph (a) shows SRTM bank height variations (at $90 \mathrm{~m}$ resolution) along the river chainage, their deviation from a subreach linear approximation (red dashed line), and the kinematic wave along the entire main stem of the Zambezi River (blue line). The plot (b) illustrates the deviation of each subreach from the kinematic wave flow profile.

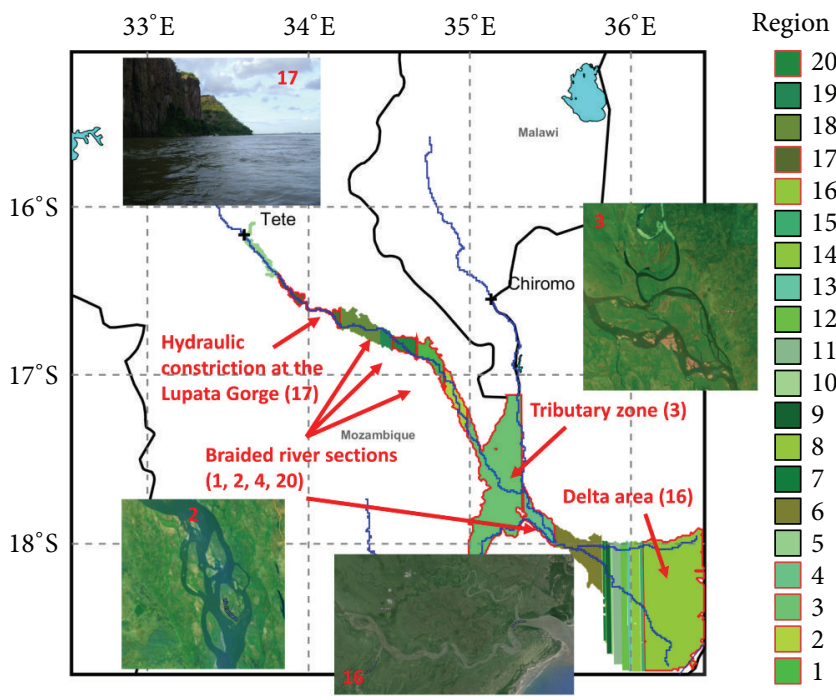

FIGURE 4: Map of individual subreaches and their floodplains, that is, regions of assimilation (colors are at random). Subreaches of hydraulic complexity (defined as $>2 \sigma$ from the kinematic wave form; see text for details) are depicted with a red outline and annotated. Note that the flooded area shown for each subreach is based on a $1: 10,000$ year flow return flood simulation, overlain as a blue outline on the SRTM topography in Figure 1. Photos are taken from Google Earth.

Unsurprisingly, subreaches in which flow is more complex, that is, sections with a high standard deviation from the kinematic wave form (as defined earlier), all yield regional and global improvements much greater than $20 \%$ in flooded area prediction, if better measurements became available for those regions. The only region that achieves only minimal improvement is region 17, which is expected since this subreach runs through the Lupata Gorge (see Figure 4) and hence better height measurements would only marginally improve predictions in this river section.

The significance of these results is further reinforced by the socioeconomic analysis conducted (Table 1) that highlights the notion that obtaining better measurement for each region results in a total global improvement (i.e., along the entire river) of $30 \%$ in flooded area prediction. As a direct consequence, a difference of more than 150,000 in people affected can be achieved and economic losses can be reduced by nearly $\$ 2$ billion (for a 1:10,000 year event), contingent of course on the accuracy of the socioeconomic input data used. Nonetheless, to put these numbers in context, the devastating 2000 flood events (orders of magnitude smaller than the $1: 10,000$ year event simulated here) caused total damage of $\$ 0.5$ billion and affected more than 5 million people in both the ZRB and Limpopo basin, according to EM-DAT.

An important point of this study is that although the targeted observation analysis (as proposed by Andreadis and Schumann [8]) can be used to assess the impact new measurements of important variables have on the prediction of flood hazard and although we showed how inclusion of socioeconomic data can augment that analysis, there is the substantial caveat that the verification model in our case was only based on higher resolution (90 m) SRTM topography and not on high accuracy elevation data, for example, from LiDAR or new InSAR technology [1]. Nevertheless, we believe this analysis to be worthwhile and suggest this type of study to be repeated for other large river areas in particular in countries deprived of high resolution floodplain DEMs so that the case for a better global DEM [2] can be supported.

As a final note, an analysis such as the one presented here should be combined with industry standard guidelines for LiDAR-type DEM acquisition. Having LiDAR-type floodplain height data over flood-prone areas would allow 


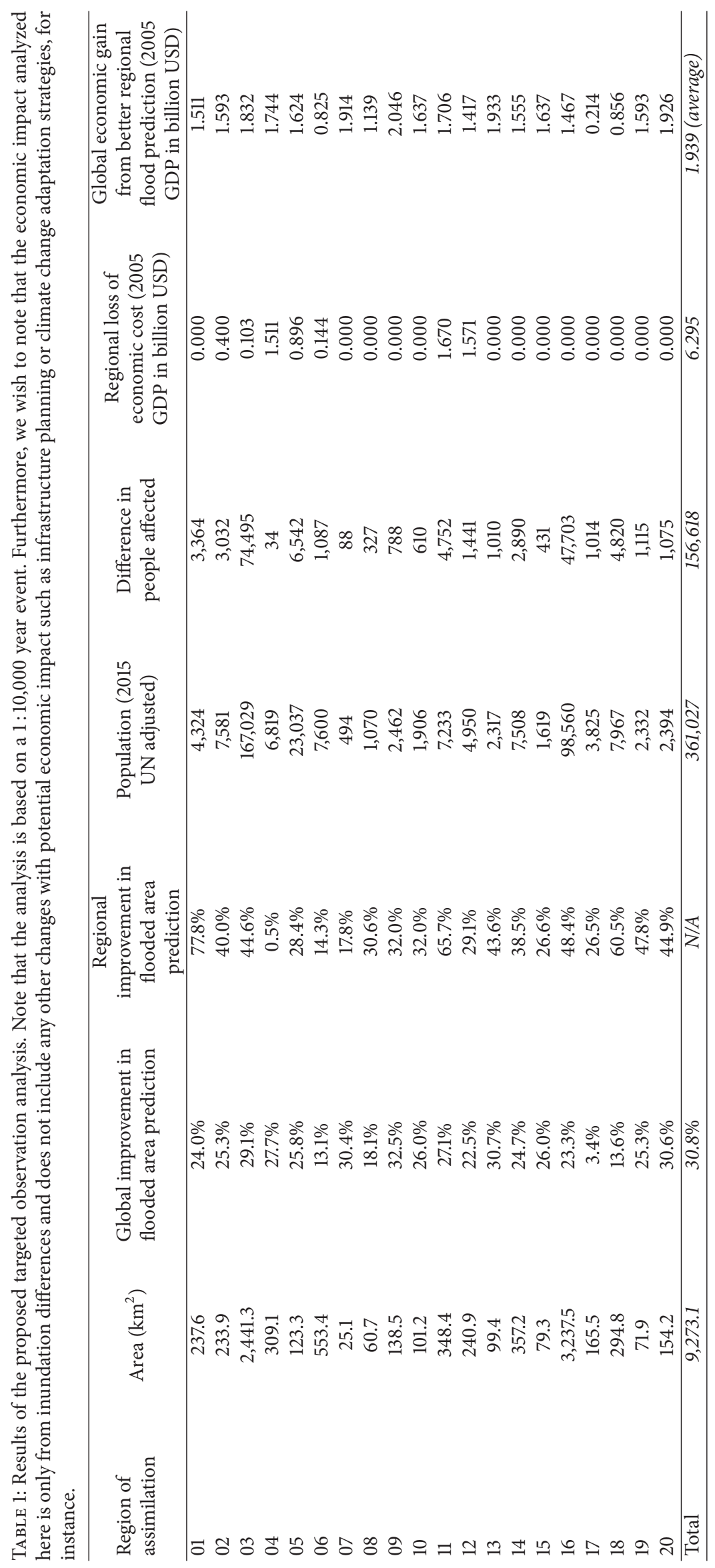


building a better 2D flood inundation model, at least for targeted regions of interest, thereby allowing more detail in the following:

(i) Understanding of local to regional floodplainchannel water storage and fluxes (including wetlands) and timing of flood wave thus achieving better flood forecasting.

(ii) Flood hazard/risk mapping for agricultural and urban areas.

(iii) Flood zone mapping associated with return period flows for assisting urban and infrastructure planning and establishing legal guidelines.

(iv) Retrieving building footprints for urban planning.

(v) Ecological and environmental flow modeling in important wetland areas, including habitat protection as well as the derivation of water quality and health indicators based on flood inundation parameters (e.g., timing of inundation and amount of water stored in floodplains).

\section{Conclusion}

There is an obvious need for a better accuracy global DEM for floodplains and coastal areas [17]. In support of this, we presented results of a detailed analysis of the impact better measurement of floodplain topography would have on the prediction of flood hazard and associated socioeconomic risk. We used the Lower Zambezi River reach and the largescale flood inundation model as developed by Schumann et al. [5] to illustrate our case. The procedure we propose is based on the targeted observation method after Andreadis and Schumann [8] which is essentially a sensitivity analysis of a Local Ensemble Transform Kalman Filter (LETKF) applied to localize the assimilation of observations or measurements. The sensitivity analysis allows one to quantify the exact impact the assimilation has locally as well as globally without the need to rerun any models, which considerably reduces the computational burden and thus appeals to large-scale applications.

For a 1:10,000 year flood event in the Lower Zambezi and focusing on the country of Mozambique, we showed that having higher resolution topography measurements available would improve our current large-scale flood inundation prediction capabilities in countries deprived of high quality DEMs by at least $30 \%$ and significantly reduce the number of people affected as well as the economic loss associated with high magnitude flooding. Although we showed considerable improvement in flood prediction for a low occurrence scenario, we believe higher accuracy topographic data would also largely improve model predictions for shorter return period events.

Although flood hazard prediction and risk analysis are difficult to perform accurately in areas that only have low resolution data available and despite the uncertainties that may arise from this limitation, we demonstrated the value of the proposed method and believe the procedure to be straightforward and simple enough to be applied to other regions. In doing so, the case for better topographic and hydrodynamic data becomes substantiated, particularly in developing nations where such data are currently often unavailable.

\section{Competing Interests}

The authors declare that they have no competing interests.

\section{Acknowledgments}

G. J.-P. Schumann and K. M. Andreadis' time was supported by a NASA THP grant (13-THP13-0042). Part of this research was carried out at the Jet Propulsion Laboratory, California Institute of Technology, under a contract with the National Aeronautics and Space Administration (NASA).

\section{References}

[1] G. J.-P. Schumann, D. Moller, and F. Mentgen, "High-accuracy elevation data at large scales from airborne single-pass SAR interferometry," Frontiers in Earth Science, vol. 3, no. 88, 2016.

[2] G. J.-P. Schumann, P. D. Bates, J. C. Neal, and K. M. Andreadis, “Technology: fight floods on a global scale," Nature, vol. 507, p. 169, 2014

[3] R. Beilfuss and D. D. Santos, "Patterns of hydrological change in the Zambezi Delta, Mozambique," Working Paper 2, US Geological Survey, Program for the Sustainable Management of Cahora Bassa Dam and The Lower Zambezi Valley, 2001.

[4] WMO, "Regional consultation meeting on Zambezi river basin flood forecasting and early warning strategy and WMO Information System (WIS) and WIGOS pilot project," Final Report, WMO and USAID, Maputo, Mozambique, Africa, 2009.

[5] G. J.-P. Schumann, J. C. Neal, N. Voisin et al., "A first large-scale flood inundation forecasting model," Water Resources Research, vol. 49, no. 10, pp. 6248-6257, 2013.

[6] P. D. Bates, M. S. Horritt, and T. J. Fewtrell, "A simple inertial formulation of the shallow water equations for efficient twodimensional flood inundation modelling," Journal of Hydrology, vol. 387, no. 1-2, pp. 33-45, 2010.

[7] Li-EDF-KP Joint Venture Consultants (Lahmeyer-Knight Peisold-Electricite de France), Mepanda Uncua and Cahora Bassa North Project Simulation of Reservoir Operation and Energy Generation on Zambezi River, Unidade Tecnica de Implentacao de Projectos Hidroelectricos, Maputo, Mozambique, 2000.

[8] K. M. Andreadis and G. J.-P. Schumann, "Estimating the impact of satellite observations on the predictability of large-scale hydraulic models," Advances in Water Resources, vol. 73, pp. 44$54,2014$.

[9] B. R. Hunt, E. J. Kostelich, and I. Szunyogh, "Efficient data assimilation for spatiotemporal chaos: a local ensemble transform Kalman filter," Physica D: Nonlinear Phenomena, vol. 230, no. 1-2, pp. 112-126, 2007.

[10] J. Liu and E. Kalnay, "Estimating observation impact without adjoint model in an ensemble Kalman filter," Quarterly Journal of the Royal Meteorological Society, vol. 134, no. 634, pp. 1327$1335,2008$.

[11] C. C. Sampson, A. M. Smith, P. B. Bates, J. C. Neal, L. Alfieri, and J. E. Freer, "A high-resolution global flood hazard model," Water Resources Research, vol. 51, no. 9, pp. 7358-7381, 2015. 
[12] J. Neal, G. Schumann, and P. Bates, "A subgrid channel model for simulating river hydraulics and floodplain inundation over large and data sparse areas," Water Resources Research, vol. 48, no. 11, Article ID W11506, 2012.

[13] C. N. H. Doll, J.-P. Muller, and J. G. Morley, "Mapping regional economic activity from night-time light satellite imagery," Ecological Economics, vol. 57, no. 1, pp. 75-92, 2006.

[14] A. M. Noor, V. A. Alegana, P. W. Gething, A. J. Tatem, and R. W. Snow, "Using remotely sensed night-time light as a proxy for poverty in Africa," Population Health Metrics, vol. 6, article 5, 2008.

[15] W. Nordhaus and X. Chen, "A sharper image? Estimates of the precision of nighttime lights as a proxy for economic statistics," Journal of Economic Geography, vol. 15, no. 1, pp. 217-246, 2015.

[16] K. M. Andreadis, G. J.-P. Schumann, and T. Pavelsky, "A simple global river bankfull width and depth database," Water Resources Research, vol. 49, no. 10, pp. 7164-7168, 2013.

[17] A. L. Simpson, S. Balog, D. K. Moller, B. H. Strauss, and K. Saito, "An urgent case for higher resolution digital elevation models in the world's poorest and most vulnerable countries," Frontiers in Earth Sciences, vol. 3, pp. 1-2, 2015. 

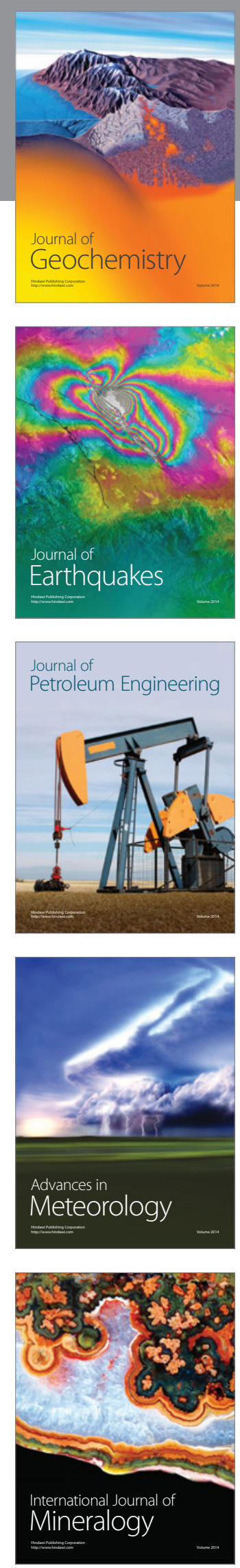
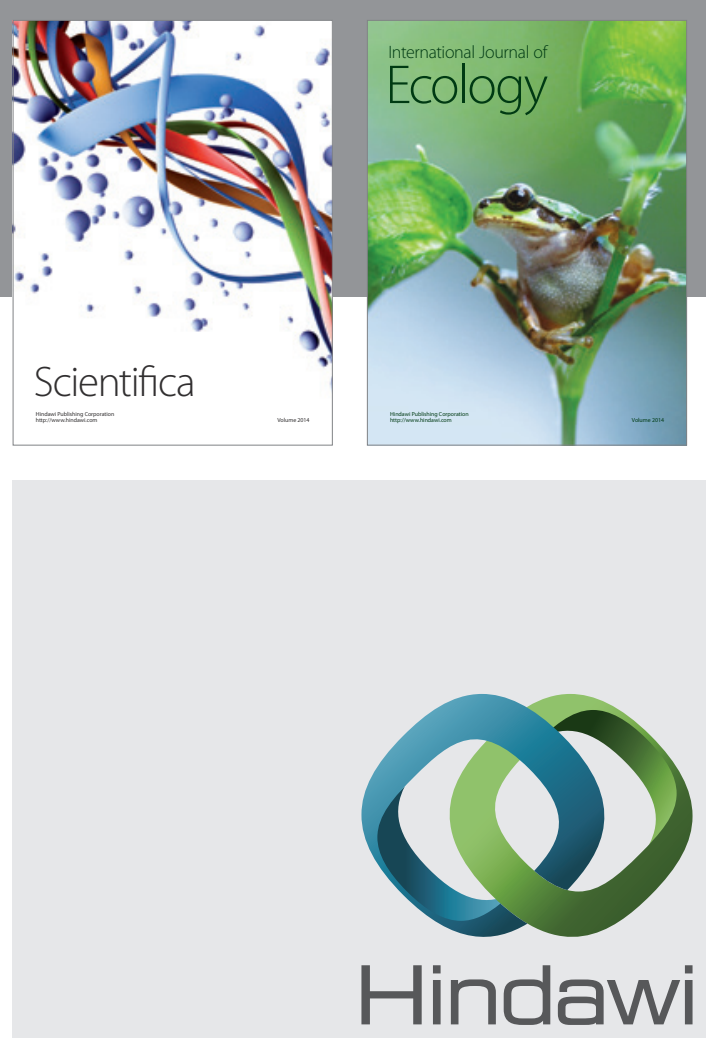

Submit your manuscripts at

http://www.hindawi.com
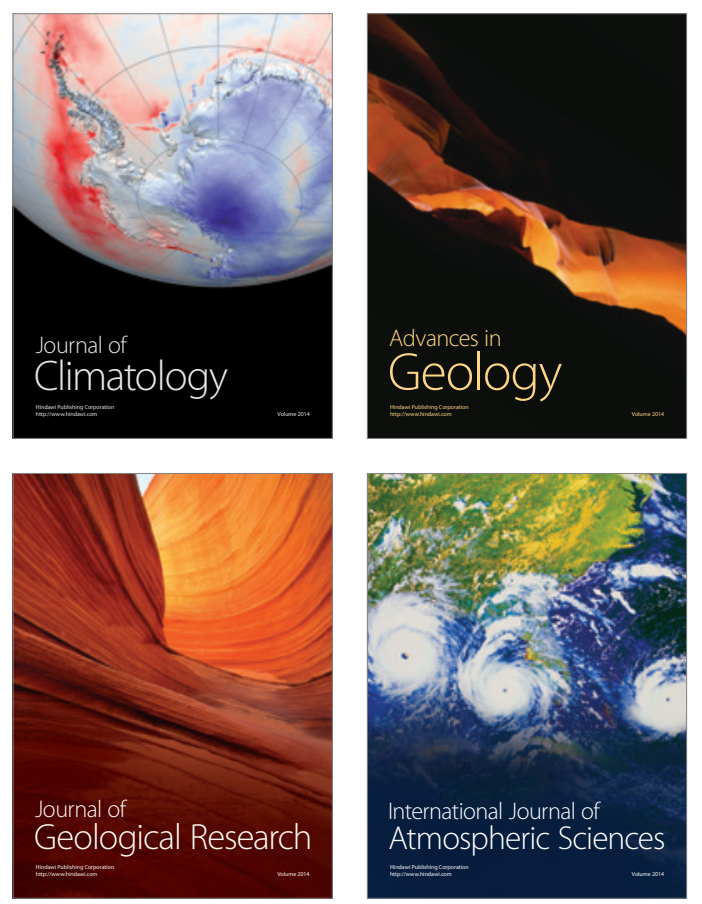

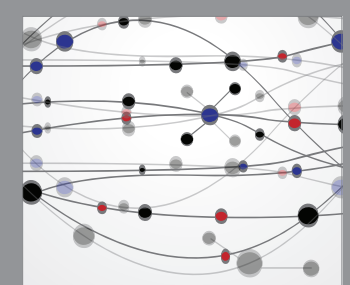

The Scientific

\section{World Journal}
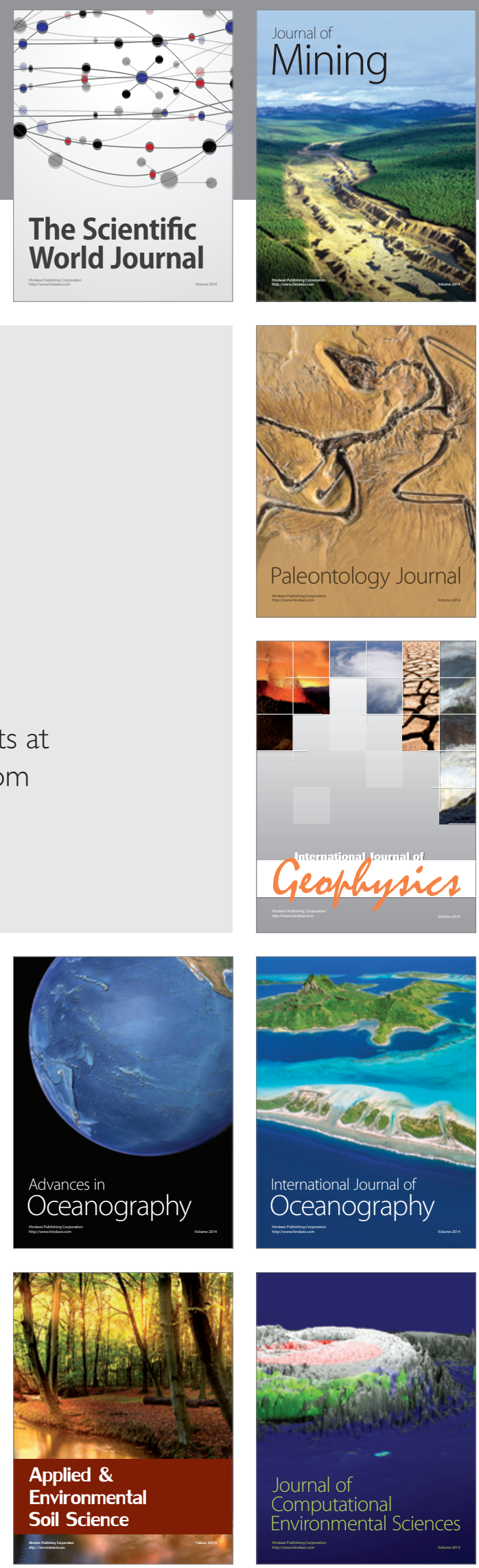